\title{
DO TEXTO AO DISCURSO: POTENCIALIZANDO O PROCESSO DE COMPREENSÃO DA LINGUAGEM
}

André Luiz Gaspari Madureira1

\section{RESUMO}

Neste artigo se propõe investigar as contribuições da análise discursiva para o processo de compreensão textual. Para tanto, antes é apresentado um posicionamento acerca da noção de texto, mediante os estudos bakhtinianos concernentes ao dialogismo. Depois é feita uma apreciação sobre o discurso, partindo-se da perspectiva da análise do discurso de linha francesa, fundamentada pelo filósofo Michel Pêcheux. A proposta de conjugação dessas posições linguísticofilosóficas se concentra na possibilidade de utilização de tais princípios para a reflexão sobre maneiras de potencializar o processo de compreensão textual. Como forma de aplicação desses princípios, é disposta uma análise textual presente em um livro didático cujo papel, neste trabalho, é o de sinalizar de que maneira o processo de compreensão é direcionado nesse tipo de suporte. A partir daí, seguese uma série de sugestões de como ampliar a perspectiva interpretativa diante do texto, ancoradas nos aportes supracitados.

Palavras-chave: Análise do discurso. Dialogismo. Discurso. Linguagem. Texto.

\section{INTRODUÇÃO}

Quando alguém procura interpretar um texto, normalmente o faz de maneira intuitiva, buscando uma lógica entre o que é dito e o que se intenciona dizer. $O$ resultado é a impressão de se ter chegado ao seu sentido próprio, à compreensão do significado específico, proporcionado pelo ato de enunciação.

A proposta gerada por meio dessa prática subjetiva de interpretação leva a crer que compreender o texto significa desvendar o seu sentido. No entanto, este, não raro, aparece como óbvio, presentificado no próprio corpo dos vocábulos, na materialidade linguística. Em outras palavras, o sentido se apresenta como evidente, cabendo ao leitor/ouvinte o papel de conhecer a estrutura gramatical (morfológica, sintática, semântica...) para, a partir daí, passar a identificá-lo.

Por essa lógica, caberia ao indivíduo o papel de adquirir conhecimentos suficientes acerca da gramática de uma língua para viabilizar a percepção do sentido da linguagem, instituindo, assim, uma relação passiva de interpretação (o 
que é, no mínimo, contraditório). Isso porque o significado é tomado como se realmente estivesse já lá, imutável, invariável, pronto para ser percebido, sem que houvesse necessidade de maiores esforços para perceber sentidos alheios ao pretendido pelo locutor.

Permeando esse campo de percepção, a prática docente por vezes instituiu, ao processo de interpretação textual, dois objetivos básicos: primeiro, o de reconhecer as peculiaridades linguísticas que compõem um determinado texto; segundo, identificar, a partir do reconhecimento dessas peculiaridades, o sentido do texto. Isso leva a perceber, por um lado, que o texto passa a ser tratado como sequência linguística que exprime sentido e, por outro, que esse sentido lhe é inerente, cabendo ao leitor/ouvinte decodificá-lo e identificá-lo.

Se essa forma de análise coloca a materialidade linguística e o sentido geral do texto no centro da observação, deixa descoberto um terreno discursivo instituído por materialidades, terreno este que fornece subsídios relevantes para o trabalho de compreensão textual. E é justamente para projetar contribuições a esse campo de abordagem que aqui se apresenta uma reflexão a respeito de como o texto vem sendo abordado em livros didáticos e de como enriquecer essa prática de análise. Mas antes é preciso pensar na relação possível entre texto e discurso.

\section{DO TEXTO AO DISCURSO}

Antes mesmo de a Linguística se tornar científica por meio dos postulados de Saussure (2003), a prática de interpretação de texto levava em consideração duas questões principais: a transparência da linguagem e o sujeito visto como único e dono do dizer.

Nesse cenário, observava-se o sentido como produto da intenção do falante, implicado no sistema comunicativo, e o papel de decodificação do leitor/ouvinte. Esse processo de comunicação foi posteriormente retratado por Jakobson (2008, p. 123). Nele, o remetente codifica a mensagem e a envia ao destinatário, o qual tem, por função, que decodificar a mensagem para atingir o sentido proposto:

O REMETENTE envia uma MENSAGEM ao DESTINATÁRIO. Para ser eficaz, a mensagem requer um CONTEXTO a que se refere (...), apreensível pelo destinatário, e que seja verbal ou suscetível de verbalização; um CÓDIGO total ou parcialmente comum ao remetente e ao 
destinatário (ou, em outras palavras, ao codificador e ao decodificador da mensagem); e, finalmente, um CONTACTO, um canal físico e uma conexão psicológica entre o remetente e o destinatário, que os capacite a ambos a entrarem e permanecerem em comunicação.

Se a mensagem é codificada, o que se espera do destinatário é uma decodificação eficiente, ou seja, uma decodificação que the permita identificar o sentido proposto, a mensagem remetida. Caso o sentido depreendido seja outro, não raro é acusada uma má decodificação, uma má interpretação por parte do destinatário.

Nesse sistema, o texto se configura como a expressão do pensamento do indivíduo, tendo a língua como código e, por isso, transparente, já que pode ser atravessada (decodificada) para se chegar ao sentido pretendido. Essa forma de se pensar sobre a língua e o texto proporciona um ambiente mecanicista em que, ao destinatário, diante de sua postura de decodificador, cabe desempenhar o papel de chegar até a mensagem proposta. Essa, por sua vez, é a expressão do pensamento do remetente, o que sinaliza para a existência de um locutor caracterizado por ser dono do dizer e fonte do sentido.

Com esses conceitos de língua e texto, vislumbra-se perceber, mediante a transparência da linguagem, o pensamento do locutor, levando a prática de leitura a um plano subjetivo. Dessa forma, as relações entre língua, ideologia e história se diluem em prol de uma abordagem que põe os anseios do indivíduo no centro da questão do sentido. O resultado obtido é o silenciamento dessas relações e a desconsideração dos efeitos de sentido que emergem do jogo da linguagem mesmo sem a anuência do locutor - e que passam a refletir na própria sociedade.

Diante da necessidade de repensar essas práticas e, com isso, a ideia de texto, surge a percepção dialógica de Bakhtin ([1929]1998) sobre a linguagem e o gênero textual. O posicionamento dialógico acerca da linguagem se coaduna à condição de gênero textual, visto que este, nos postulados bakhtinianos, não é tido, em sua constituição, por um viés individual, mas interindividual. Os gêneros só existem enquanto tais na relação coletiva em determinada época, caracterizando-se como produto social. No âmbito da comunicação, servem para estabilizá-la, funcionando como "entidades sócio-comunicativas e formas de ação social" que não podem ser contornadas (MARCUSCHI, 2007, p. 19). 
O texto, portanto, se caracteriza como uma realização dialógica, coletiva, e deve ser remetido às condições sociais em que ocorre. Sob esse ponto de vista, a análise do texto pode ser potencializada com a contribuição dos estudos oriundos da análise do discurso de linha francesa (doravante AD), que surge com a proposta de instituir um plano de leitura diferente, originário de rupturas voltadas principalmente à linguagem, ao sujeito, ao discurso e à ideologia. A ideia é implementar uma teoria não subjetiva de leitura e, com isso, aproximar a prática de observação do sentido de um terreno mais materialista e, por consequência, menos subjetivo.

Essas rupturas - como o próprio termo já sinaliza - visam romper com certos modos de se conceber esses termos, e não relegá-los a outro terreno de análise. $\mathrm{Na}$ $A D$, tanto a linguagem quanto o sujeito, o discurso e a ideologia tornam-se elementos fundamentais para a sua constituição. No entanto, não se inscrevem como antes. A linguagem não é mais vista como transparente, e sim por meio da opacidade que lhe é inerente; o sujeito se distancia da propriedade física - ou de ser termo essencial da oração -, para se relacionar ao lugar social de onde emanam dizeres; o discurso não se caracteriza mais como o produto eminentemente linguístico do ato de fala de alguém, e sim como efeitos de sentido entre interlocutores; a ideologia deixa de se circunscrever ao campo das ideias e passa a ser pensada em sua condição materialista, ao remeter a relações de classe.

Nesse entremeio teórico, o texto se apresenta como lugar de interação cuja constituição não se dá apenas por meio da linguagem, mas também da história, da sociedade, da ideologia. Sobre sua condição dialógica, Koch (2006, p. 17) esclarece:

(...) na concepção interacional (dialógica) da língua, na qual os sujeitos são vistos como atores/construtores sociais, o texto passa a ser considerado o próprio lugar da interação e os interlocutores, como sujeitos ativos que dialogicamente - nele se constroem e são construídos. Dessa forma há lugar, no texto, para toda uma gama de implícitos, dos mais variados tipos, somente detectáveis quando se tem, como pano de fundo, o contexto sociocognitivo dos participantes da interação.

Por essa concepção, a análise de texto recebe contribuições da perspectiva do discurso, propiciando uma abordagem que vai além das relações gramaticais. Junto a aspectos da textualidade (principalmente aos que estabelecem relações de coesão e coerência), condições sócio-históricas e ideológicas passam a permear o plano de interpretação de texto, tornando-o, assim, um terreno fecundo e propício a 
serem estabelecidas percepções mais complexas - e, por isso, menos evidentes - a respeito do intrincado jogo da linguagem.

\section{O TEXTO NO LIVRO DIDÁTICO}

Como maneira de pensar sobre propostas de intervenção na leitura, presentes em livros didáticos, foi selecionada uma tirinha, produzida pelo cartunista Luís Augusto Conceição Gouveia. Na narrativa, Lucas, um personagem mudo, passa a refletir sobre uma circunstância corriqueira. A tirinha se apresenta no livro didático Diálogo: língua portuguesa, $6^{\circ}$ ano (BELTRÃO e GORDILHO, 2009, p. 160).

Para introduzir os quadrinhos da tirinha, no livro didático é indicado o seguinte comando: "5. Leia esta outra tirinha. Nela, o personagem Lucas ajuda o leitor a refletir sobre algumas das ações feitas pelo homem no cotidiano". No decorrer da tirinha, Lucas, ao caminhar pela rua, se depara, no primeiro quadrinho, com um bueiro aberto. No segundo, pensa: "Como deixam um bueiro aberto?". No último, conclui, sempre sob forma de pensamento: "Não sabem que tem um país andando às cegas por aí?"

Depois da apresentação da tirinha, aparecem estas perguntas:

a) O que é narrado na tirinha?

b) O que e em quem o personagem pensa nesse momento?

c) No segundo quadrinho, Lucas emprega o verbo 'deixam', na $3^{\text {a }}$ pessoa do plural. É possível identificar, na oração, o que ou quem é responsável pela ação expressa pelo verbo?

d) Que forma verbal, empregada por Lucas no terceiro quadrinho, revela que ele não quer determinar o sujeito responsável pela ação?

(BELTRÃO e GORDILHO, 2009. p. 160).

Tendo em vista a necessidade de se observar a reflexão sugerida no livro didático, utilizou-se o exemplar do professor. A partir daí, foi possível acessar as propostas de resposta, as quais são apresentadas na sequência:

- Proposta de resposta para a questão a): "Lucas, ao andar na rua, vê um bueiro sem a tampa e se surpreende, se questiona".

- Proposta de resposta para a questão b): "Ele pensa nas pessoas que agem de forma inconsequente e que não se preocupam com o que possa acontecer com o seu semelhante". 
- Proposta de resposta para a questão c): "Embora exista um sujeito responsável pela ação expressa pelo verbo, não é possível identificá-lo na oração".

- Proposta de resposta para a questão d): "'Sabem'”.

A relação pergunta/resposta na questão a) evidencia a necessidade de se estabelecer uma leitura que tome o texto em seu sentido amplo. $O$ ato de ver o bueiro aberto - presente no primeiro quadro - não está descrito em palavras, e sim por meio da imagem de Lucas olhando para o bueiro, mediante o texto não-verbal. Já a ideia de surpresa e de questionamento é percebida a partir da leitura das próprias palavras, no texto verbal.

No par pergunta/resposta da questão b), procura-se identificar o alvo do pensamento de Lucas, identificação esta que se direciona à circunstância prática da vida corriqueira do ser humano. Remete-se, assim, ao comportamento inconsequente como algo nocivo para a manutenção do bem-estar das pessoas, como é o caso concreto de se deixar um bueiro aberto.

Já na relação pergunta/resposta na questão c), para a análise do sujeito ao qual Lucas se refere, no segundo quadro, instaura-se o posicionamento normativo. Diante desse ponto de vista, quando o verbo está na terceira pessoa do plural, sem que qualquer elemento na frase se configure como núcleo do sujeito, dá-se a ocorrência do sujeito indeterminado.

Novamente, essa perspectiva normativa da língua ocorre no par pergunta/resposta na questão d), ratificando a posição prescritiva acerca da identificação do sujeito indeterminado.

\section{INSUFICIÊNCIAS NA RELAÇÃO PERGUNTA/RESPOSTA}

Apesar da busca por certo grau de compreensão textual, as propostas de pergunta/resposta apresentam insuficiências que devem ser evidenciadas e discutidas para que se estabeleçam ações direcionadas à potencialização da atividade interpretativa.

Uma dessas insuficiências se volta à ausência de uma ação efetiva que invista no desenvolvimento da abstração por parte do leitor. O que se observa, na análise presente no livro didático, é a evidenciação do que ocorre na prática, do 
acontecimento descrito na tirinha. Nesse sentido, a proposta é centralizada em descrever apenas o que está posto, caracterizando a atividade de compreensão de texto como uma tarefa de afirmação do óbvio.

A prática da afirmação do óbvio tende, por sua vez, a silenciar questões não percebidas nesse tipo de análise e, por isso, a excluir um elemento de motivação do ato de leitura: a percepção do que subjaz à linguagem. Tal prática leva a crer na transparência da linguagem, na evidência do sentido e no processo de decodificação como realidades (e não impressões), as quais influenciam na concepção de leitura, tomando-a como um processo eminentemente mecânico de identificação do sentido. Desse modo, se, por um lado, a primeira relação entre pergunta e resposta recobre a circunstância da enunciação, por outro, deixa descoberto um campo abstrato do processo interpretativo, um campo que tende a propulsionar a percepção crítica e analítica.

Em um movimento de coesão textual, o segundo par de pergunta e resposta ratifica os princípios descritos no primeiro. Ao se sugerir a revelação do que o personagem pensa, a linguagem é projetada como produto do pensamento do sujeito, tornando-o a fonte do dizer, o ponto de constituição dos sentidos. Por essa posição, interpretar significa acessar o sentido proposto pelo sujeito, o que implica a impossibilidade de transcender os limites subjetivos, a custo de realizar uma interpretação equivocada. Na própria proposta sugerida, o pensamento de Lucas sinaliza exclusivamente para a constatação da realidade circunstancial, pontuando o comportamento inconsequente das pessoas que não pensam no próximo.

Esse pensamento está reproduzido linguisticamente. No entanto, não é capaz, por si só, de recobrir toda a impressão que um sujeito tem acerca de uma determinada situação. Aliás, a reprodução linguística do pensamento de Lucas se constitui como uma imagem acústica que seria reproduzida em sua fala - mas não o é, devido ao fato de ser mudo -, e não enquanto a totalidade de impressões que, até certo ponto, são inacessíveis ao próprio sujeito, cuja constituição psíquica se dá não só com o consciente, mas também com o inconsciente.

Diante disso, surgem ainda os seguintes questionamentos: primeiro, como se pode identificar a impressão do pensamento do personagem se este é um personagem (com perdão da repetição enfadonha!), resultado da ação inventiva de um autor? Segundo, por que não atentar realmente para o fato de que se trata de 
um gênero textual específico (tirinha) e mobilizar parte de suas condições de produção na análise (o fato de que a tirinha foi feita por um cartunista, que é publicada em um site, que se destina a um público mais amplo.)?

Com as duas últimas propostas de pergunta e resposta, há a impressão de que se busca trabalhar o conhecimento normativo de forma contextualizada, porém, dá-se apenas atenção à estrutura do vocábulo, o que limita a interpretação à apreciação morfológica. Nessa perspectiva, o contexto abordado se restringe ao normativo, o que inviabiliza analisar os termos linguísticos pela função que desempenham em determinadas estruturas. Exclui-se, assim, uma oportunidade de transcender, na proposta do livro didático, os limites prescritivos e de oportunizar uma análise funcional de aspectos morfossintáticos.

O que ainda se observa, nessas duas propostas, é o trabalho equivocado de análise que, circunscrita à apresentação da forma verbal na frase, gera a ideia de indeterminação do sujeito. No entanto, na resposta da segunda questão, determinase o sujeito: "pessoas que agem de modo inconsequente". Portanto, é possível identificar quem se responsabiliza pela ação verbal ("as pessoas que agem de modo inconsequente"!), evidenciando uma contradição entre as respectivas respostas sugeridas. Desse modo, fica evidente que não se trata de uma análise contextualizada, e sim "pretextualizada", a partir da qual o texto se torna apenas um pretexto para a identificação do óbvio e para a apresentação de posições normativas.

Diante das insuficiências pontuadas, é preciso buscar meios de potencializar o processo de compreensão textual. Segue-se, pois, uma proposta de reflexão, baseada na análise do discurso de linha francesa e de pressupostos bakhtinianos, cujos resultados podem servir para tornar a prática de leitura um evento de descoberta e de desenvolvimento do senso crítico.

\section{PERCEPÇÕES DISCURSIVAS DO TEXTO}

Tratar de percepções discursivas subjacentes ao texto implica estabelecer um vínculo entre a linguagem e sua exterioridade, de modo que sejam percebidas as condições a partir das quais o dizer se materializa. Por esse viés, o contexto se 
constitui como um dos elementos que propiciam a constituição de determinados efeitos de sentido, o que o torna fundamental na atividade de compreensão de texto.

Para resgatar parte do contexto situacional, é possível recorrer ao próprio livro didático, que apresenta informações dessa natureza, caracterizando tanto o lugar social do autor, quanto os suportes em que as tirinhas se materializam:

Luís Augusto Conceição Gouveia nasceu em Salvador (BA) em 1971. Criou o Fala Menino!, uma turma de personagens cujas travessuras são contadas em tirinhas publicadas em jornais de grande circulação em alguns estados brasileiros e, também, em seus livros. Seu trabalho foi premiado várias vezes por apresentar uma reflexão sobre problemas da atualidade. Lucas, personagem da tirinha, é mudo e dialoga com o mundo dos adultos de um jeito muito especial, bem-humorado. (BELTRÃO e GORDILHO, 2009, p. 160).

No plano discursivo, a análise se distancia da percepção de pensamentos, de intenções do indivíduo, mesmo porque não se pode garantir materialmente o valor dessas questões (O indivíduo realmente disse o que pensou? Mas, se ele garantir que não quis dizer? Será que o que foi dito reflete seu "real" pensamento?). Por isso, o que interessa discursivamente não é identificar o que pensa Luís Augusto Conceição Gouveia, mas de que lugar social ele se coloca.

Desse modo, as condições de produção destacam o lugar social de onde emana o dizer: o lugar social de escritor, de cartunista. Os suportes em que o texto se materializa são "jornais de grande circulação" e livros. A identificação entre texto e gênero possibilita pensar acerca dos aspectos da textualidade, das relações de sentido proporcionadas por critérios de coerência e de coesão, passíveis de serem identificados na tirinha. A partir daí, tanto a funcionalidade, quanto o caráter formal do texto passam a fazer parte dos elementos de análise. Além disso, os efeitos de sentido que emanam se direcionam à critica social, instaurada por meio do humor, validados no próprio contexto de premiação.

Esses dados, apesar de serem, até certa medida, mobilizados no livro didático, não são devidamente aproveitados na análise nele apresentada. Prova disso é que, na questão a), é simplesmente proposta a reprodução linguística da ação narrada. O fato desses materiais - como a tirinha - permearem suportes que os propagam nacionalmente, aliando-se a isso o fato de terem recebido vários prêmios devido à propriedade de disseminar reflexões acerca do comportamento social, já se coloca como um indício de problematização. Por isso, circunscrever a 
análise a um plano superficial, pautado na descrição/paráfrase do que está posto, inviabiliza a investigação acerca dos efeitos de sentido mais reflexivos, evidenciados pelo comportamento da própria sociedade (como, por exemplo, o de referendar o valor crítico, sócio-político das obras por meio de premiações).

$\mathrm{Na} A D$, a linguagem é o lugar de materialização do discurso. Este, por sua vez, é onde a ideologia se materializa, tendo em vista que passa a ser tida não mais como ideia, e sim por meio da definição de Formação Ideológica (FI). De acordo com Pêcheux e Fuchs (1997, p. 166), "cada FI constitui um conjunto complexo de atitudes e de representações que não são nem 'individuais' nem 'universais' mas se relacionam mais ou menos diretamente a posições de classe em conflito umas com as outras". Por esse viés, é percebida a partir da práxis social, das relações interpessoais, dos conflitos de classe. A conjuntura sócio-histórica, portanto, sinaliza para a presença da ideologia. Desse modo, abordá-la implica analisar as relações sociais, lançando-se à reflexão de como propiciam certos efeitos de sentido. É dessa maneira que se concebe a ideologia enquanto materialidade do/no discurso.

No entanto, o acesso a esse campo de materialidades se dá por meio da linguagem. Nessa, encontram-se pistas, indícios da presença de discursos e das relações sociais que entram em confluência para a instauração de certos efeitos de sentido. No plano da AD, a configuração do signo linguístico, proposta por Saussure, recebe um deslocamento. Para Pêcheux (1995, p. 262), "uma palavra, uma expressão ou uma proposição não têm sentido que lhes seria próprio, preso a sua literalidade". Não se pode, portanto, conceber a relação estrita entre significante e significado. A palavra se torna desprovida de significado, até que esteja voltada a uma formação discursiva. Assim, a relação entre palavra e (efeitos de) sentido se estabelece diante do contexto em que o dizer se materializa.

Diante desses critérios de investigação, parte-se para o reconhecimento tanto de pistas linguísticas (e, nesse caso, é interessante recorrer às condições de textualidade), como de condições situacionais e sócio-históricas. Na tirinha, os enunciados "Como deixam um bueiro aberto?" e "Não sabem que tem um país andando às cegas por aí?", aliados às imagens, revelam um contexto situacional pelo qual passa o personagem Lucas, em que o bueiro representa um buraco escuro no qual as pessoas podem cair. No jogo de paráfrase e polissemia, essa circunstância (re) significa discursivamente a expressão popular "entrar pelo cano" 
que, nas condições sinalizadas, se coaduna a um efeito de sentido negativo, remetido a um teor de insatisfação.

Ao passar para o reconhecimento de pistas linguísticas, evidencia-se que os termos "país" e "às cegas" expandem a análise para além da mera representação circunstancial. Depois de questionar o porquê de o bueiro ser deixado aberto, no terceiro quadro, há a impressão de que Lucas irá pontuar que alguém pode cair nele, a tomar pelo início do segundo enunciado: "Não sabem que (...)". No entanto, a expectativa é quebrada pela continuação do dizer: "(...) tem um país andando às cegas por aí?". Numa tentativa de paráfrase, observa-se que não se trata de pessoas cegas andando por aí, e sim, "um país andando às cegas".

Esse jogo de sentidos suscita a instauração de diferentes planos de leitura. Por isso o texto pode ser lido pelo viés pontual, atribuindo-se responsabilidade a "pessoas que agem de forma inconsequente", ou por uma perspectiva sociopolítica, remetendo, assim, aos dirigentes do "país" que o conduzem "às cegas" e, portanto, ao caráter ineficiente das gestões públicas. Quando se percebe 0 efeito proporcionado pelo segundo plano de leitura, instaura-se a perspectiva humorística da tirinha. Isso se deve ao deslizamento de sentidos que ocorre, bem como à reinscrição da ideia de comportamento inepto do político brasileiro, que está presente no imaginário social. A própria escolha das palavras gera tal deslizamento e se coaduna com o lugar social de onde se fala, bem como ao contexto de instauração do dizer. Desse modo, na tirinha são instaurados efeitos de sentido sócio-políticos, remetendo à ineficiência da gestão pública no Brasil.

Por essa análise, não está em questão se o personagem ou o autor pensaram nesses efeitos, mas que são possíveis, devido às condições sócio-históricas e ideológicas em que o dizer se constitui. Nessa perspectiva, apresenta-se uma alternativa de se trabalhar com questões gramaticais de forma mais coerente, por meio da reflexão acerca das implicações de substituir "país" por "pessoas" e "às cegas" por "cegas". Nesse segundo par de palavras, há, por exemplo, modificação da classificação morfológica e sintática das expressões, causada pelas condições em que aparecem nos dizeres (seja no estabelecido na tirinha ou no parafrástico sugerido). Como se vê, trabalhar a variação de sentidos em conjunto com a relação morfossintática estabelecida no dizer e com o contexto sócio-histórico é um caminho possível para a reflexão contextualizada sobre a gramática. 
Os conhecimentos morfossintáticos, mediante essa análise, são acionados em prol de uma abordagem funcional, relacionados ao contexto de constituição do dizer. As condições de textualidade estabelecem um vínculo com as relações de discursividade, proporcionando um ambiente de leitura menos óbvio e, portanto, mais atraente para quem busca se surpreender diante do jogo da linguagem.

\section{CONCLUSÃO}

Ir do texto ao discurso não significa causar uma ruptura que anule uma perspectiva de análise em favor da outra. Ao contrário, a passagem do texto ao discurso deve integrar ambos os domínios, num movimento de complementaridade.

A integração entre estudos de texto e discurso já vem sendo debatida e compreendida como uma postura positiva para o ensino. Ao abordar a questão histórica da crise do ensino de língua, Gregolin (2007, p. 54) salienta que, como um dos "principais ganhos dessa crise está a idéia, hoje, de que a língua deve ser ensinada sob a perspectiva discursiva". Desse modo, as condições de textualidade recebem um acréscimo com a incorporação da ideologia, dos lugares sociais, das arenas dialógicas em que diferentes vozes digladiam e o complexo movimento interdiscursivo se faz presente.

Nesse cenário, compreender o texto se torna uma atividade investigativa a partir da qual não há lugar para a mera reprodução do que está evidente na linguagem. A percepção de aspectos formais não se encerra em si mesma, e a pesquisa sobre o contexto ganha funcionalidade. Isso leva a potencializar a ação interpretativa, a desenvolver no leitor a propriedade de amarrar os nós da/na linguagem.

Ao serem identificadas as relações linguísticas que compreendem a estrutura do dizer, sinaliza-se para indícios de silenciamentos cuja propriedade é integrar o funcionamento interdiscursivo e, com isso, autorizar a instauração de certos efeitos de sentido. Assim, os elementos sócio-históricos e ideológicos passam a funcionar em conjunto com a estrutura linguística, contribuindo para se instituir uma prática de leitura eficiente, na qual o contexto é realmente mobilizado em favor da análise, e sem mais pretextos! 


\title{
NOTAS
}

${ }^{1}$ Graduado em Letras Vernáculas pela Universidade Católica do Salvador (UCSal), especialista em Estudos Linguísticos e Literários, mestre em Letras e Linguística e doutor em Letras pela Universidade Federal da Bahia (UFBA). Professor de Linguística da Universidade do Estado da Bahia (UNEB), Campus XVI.

\section{FROM TEXT TO SPEECH: EMPOWERING THE PROCESS OF LANGUAGE UNDERSTANDING}

\begin{abstract}
In this article it is proposed the investigation of the contributions of discourse analysis for the process of textual comprehension. For that, a concept of textual comprehension process through Bakhtinian dialogism is presented. Then an appreciation of the discourse is carried out through French orientation based on the concept of the philosopher Michel Pêcheux. The proposal of the conjugation of such philosophical, linguistic positions lays on the possibility of using those concepts to find ways to strengthen the process of textual comprehension. In order to apply this principle, it is made available a textual analysis of a didactic book whose role in this article is to signal which way the process of comprehension takes by using this kind of support. From this point on, a set of suggestions follows so as to increase the interpretative perspective of the text based on the above supports.
\end{abstract}

Key words: Discourse analysis. Dialogism. Discourse. Language. Text.

\section{REFERÊNCIAS}

BAKHTIN, Mikhail (Volochinov). Marxismo e filosofia da linguagem. Trad. Michel Lahud e Yara Frateschi Vieira. 8. ed. São Paulo: Hucitec, [1929] 1988.

BELTRÃO, Eliana Santos; GORDILHO, Tereza. Diálogo: língua portuguesa: $6^{\circ}$ ano (Manual do Professor). São Paulo: FTD, 2009.

FÁVERO, Leonor Lopes; KOCH, Ingedore Villaça. Lingüística textual: introdução. São Paulo: Cortez, 2000.

GREGOLIN, Maria do Rosário. O que quer, o que pode esta língua? Teorias lingüísticas, ensino de língua e relevância social. In: CORREA, Djane Antonucci. (Org.). A relevância social da lingüística: linguagem, teoria e ensino. São Paulo: Parábola Editorial, 2007.

JAKOBSON, Roman. Lingüística e comunicação. Trad. Izidoro Blikstein e José Paulo Paes. 21. ed. São Paulo: Cultrix, 2008. 
$\mathrm{KOCH}$, Ingedore Villaça. Desvendando os segredos do texto. 5. ed. São Paulo: Cortez, 2006.

MARCUSCHI, Luiz Antônio. Gêneros textuais: definição e funcionalidade. In: DIONISIO, A. P.; MACHADO, A. R.; BEZERRA, M. A. (Org.). Gêneros textuais e ensino. 5. ed. Rio de Janeiro: Lucerna, 2007.

PÊCHEUX, Michel. Semântica e discurso: uma crítica à afirmação do óbvio. Trad. Eni Pulcinelli Orlandi. 2. ed. Campinas: Editora da UNICAMP, 1995.

PÊCHEUX, M.; FUCHS C. A propósito da análise automática do discurso: atualização e perspectivas (1975). In: GADET. F.; HAK T. (Orgs.). Por uma análise automática do discurso: uma introdução à obra de Michel Pêcheux. Trad. Bethania S. Mariani et al. 3. ed. Campinas: Editora da UNICAMP, 1997.

SAUSSURE, Ferdinand de. Curso de lingüística geral. Prefácio de Charles Bally; Albert Sechehaye. Trad. Antonio Chelini, José Paulo Paes e Izidoro Blikstein. 25. ed. São Paulo: Cultrix, 2003. 


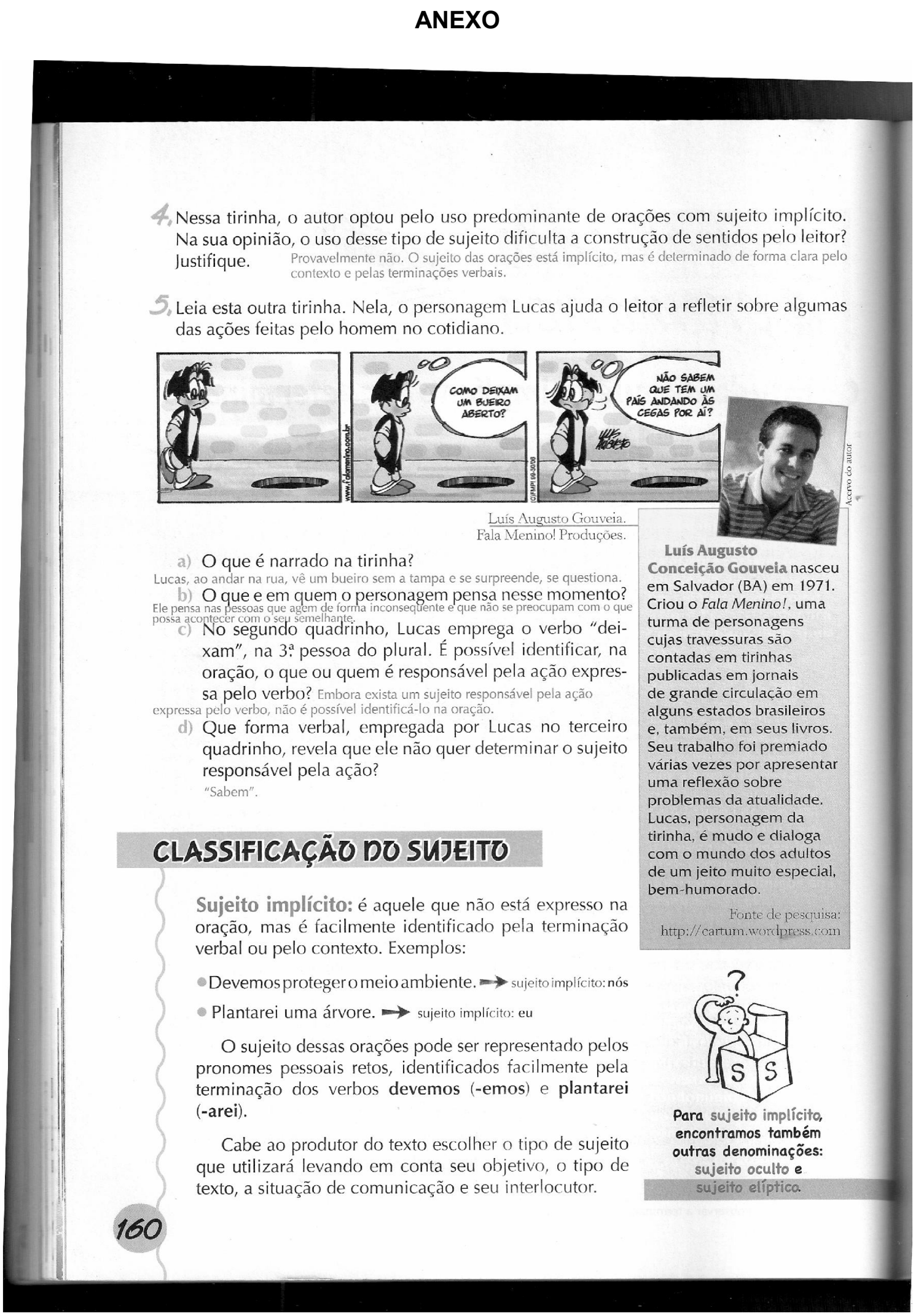

